\title{
Amino acid substitutions in the pore affect the anomalous mole fraction effect of $\mathrm{Ca}_{\mathrm{v}} 1.2$ channels
}

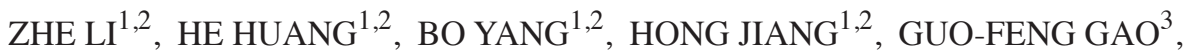 \\ BLAISE Z. PETERSON ${ }^{3}$ and CONG-XIN HUANG ${ }^{1,2}$
}

\author{
${ }^{1}$ Department of Cardiology, Renmin Hospital of Wuhan University, and ${ }^{2}$ Cardiovascular Research Institute \\ of Wuhan University, Wuhan, Hubei 430060, P.R. China; ${ }^{3}$ Department of Cellular and Molecular Physiology, \\ Pennsylvania State University College of Medicine, Hershey, PA 17033-0850, USA
}

Received August 7, 2012; Accepted November 26, 2012

DOI: $10.3892 / \mathrm{mmr} .2012 .1210$

\begin{abstract}
The anomalous mole fraction effect (AMFE) is an important indicator of ion-ion interactions in the pore of voltage-gated $\mathrm{Ca}^{2+}$ channels (VGCCs). The residues at position 1144 that differ in several classes of VGCCs are important to the permeation of the pore. Phe-1144 $\left(\mathrm{F}, \mathrm{Ca}_{\mathrm{v}} 1\right)$ was substituted with glycine $\left(\mathrm{G}, \mathrm{Ca}_{\mathrm{v}} 2\right)$ and lysine $\left(\mathrm{K}, \mathrm{Ca}_{\mathrm{v}} 3\right)$ and the effects of mutation on the voltage and concentration dependency of AMFE were observed. Whole-cell currents were recorded in external solutions with $\mathrm{Ca}^{2+}$ and $\mathrm{Ba}^{2+}$ at the indicated ratios with a total divalent cation concentration of 2,10 or $20 \mathrm{mM}$, at holding potentials from -80 to $-20 \mathrm{mV}$. Results showed the ratio of $\mathrm{Ba}^{2+}$ to $\mathrm{Ca}^{2+}$ currents determined at $2 \mathrm{mM}$ to be different from that determined under higher concentrations for wild-type channels but this ratio was not different when tail currents were evoked at different potentials. AMFE was greatest at relatively positive potentials $(-20 \mathrm{mV})$ and when the total divalent cation concentrations were kept low $(2 \mathrm{mM})$. AMFE was attenuated for $\mathrm{F} / \mathrm{G}$ while it was accentuated for F/K compared with wild-type, respectively. The results demonstrated that glycine and lysine substitutions of Phe-1144 affect AMFE through different mechanisms. Additionally, residues at position 1144 were shown to be major determinates of channel permeation of several classes of VGCCs.
\end{abstract}

\section{Introduction}

L-type calcium channels transport $\mathrm{Ca}^{2+}$ into myocytes and are important in the regulation of heart rhythm, excitationcontraction coupling and gene expression (1). Voltage-gated

Correspondence to: Dr Cong-Xin Huang, Department of Cardiology, Renmin Hospital and Cardiovascular Research Institute, Wuhan University, 238 Jiefang Road, Wuhan, Hubei 430060, P.R. China

E-mail: rmhwhu@gmail.com

Key words: anomalous mole fraction effect, mutation, permeation, pore, selectivity filter
$\mathrm{Ca}^{2+}$ channels (VGCCs) are heteromultimeric complexes composed of $\alpha 1, \beta, \alpha 2 / \delta$ and occasionally $\gamma$-subunits. The pore-forming $\alpha 1$ subunit contains all the structural determinants required for ion permeation, voltage-dependent gating and drug binding. The membrane topology of the $\alpha 1$ subunit consists of four homologous domains (I, II, III and IV), with six transmembrane segments (S1-S6) in each (Fig. 1A). Segments connecting with S5 and S6 in each domain contain four negatively charged glutamate residues that shape the pore of the channel and form binding sites for ions, known as the selectivity filter (EEEE locus) (2).

The nature of multi-ion permeation through the pore of voltage-gated $\mathrm{Ca}^{2+}$ channels has previously been investigated. Hess and Tsien (3) and Almers and McCleskey (4) suggested that $\mathrm{Ca}^{2+}$ binds the channel more strongly than other ions and that there is an electrostatic interaction between ions within the channel. Such channel selectivity and ion interactions demonstrate a phenomenon known as the anomalous mole fraction effect (AMFE). The AMFE arises when a mixture of two permeant ions produce less current than either permeant ion alone at the same total ion concentration. The AMFE is a complex phenomenon that depends on the holding voltage, total ion concentration and the intrinsic binding properties of the channel. Thus, AMFE is an important indicator of ion-ion interactions in the pore of voltage-gated $\mathrm{Ca}^{2+}$ channels.

$\mathrm{Ba}^{2+}$ currents through L-type $\mathrm{Ca}^{2+}$ channels, as well as most other high-voltage-activated $\mathrm{Ca}^{2+}$ channels, are approximately twice the size of $\mathrm{Ca}^{2+}$ currents $(2,5)$. The differences between $\mathrm{Ba}^{2+}$ and $\mathrm{Ca}^{2+}$ conductance depend on the binding affinities of single cations to the selectivity filter of the channel $(3,4,6,7)$. The binding affinity of a single $\mathrm{Ba}^{2+}$ ion to the selectivity filter is reported to be 70 -fold lower than that of $\mathrm{Ca}^{2+}(8)$. Therefore, the repulsive forces exerted by the entry of a second ion promote the exit of a $\mathrm{Ba}^{2+}$ ion more readily than $\mathrm{Ca}^{2+}$, which increases the exit rate and ionic flux. However, how ions permeate through the pore of voltage-gated $\mathrm{Ca}^{2+}$ channels and interact with a second ion remains a controversial topic.

There are several numeric simulation models dependent on the binding-repulsion events in the pore that predict the ion-ion interactions in the pores of $\mathrm{Ca}^{2+}$ channels. The $\mathrm{Ca}^{2+}$ channel model of a pair of high-affinity binding sites and ion interactions with electrostatic repulsion is widely 
A

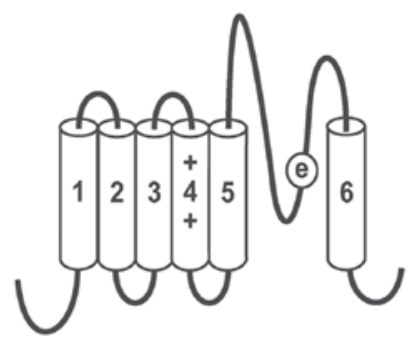

Figure 1. Phe-1144 residue in the pore segment of domain III. (A) The membrane topology of the $\alpha 1$ subunit consists of four homologous domains (domain III is shown), each consisting of six transmembrane segments (S1-S6). The selectivity filter is formed by four conserved glutamate residues (E), each residing on one of the four S5-S6 connecting loops. The intracellular portions of the four S6 transmembrane segments form the inner lining of the permeation pathway and the activation gate. The S4 segment from each repeat is an amphipathic helix consisting of several positively charged lysine or arginine residues and functions as the voltage sensor that couples membrane depolarization to channel activation. (B) Alignment of the domain II pore segment from each of the 10 -voltage-gated $\mathrm{Ca}^{2+}$ channel family members. The alignments are highly conserved. At position 1144 (boxed) where located neighboring Glu-1145, all L-type $\mathrm{Ca}^{2+}$ channels $\left(\mathrm{Ca}_{\mathrm{v}} 1.1-4\right)$ possess a phenylalanine $(\mathrm{F})$. However, all non-L-type high-voltage-activated $\mathrm{Ca}^{2+}$ channels $\left(\mathrm{Ca}_{\mathrm{v}} 2.1-3\right)$ possess a glycine $(\mathrm{G})$ and all low-voltage-activated $\mathrm{Ca}^{2+}$ channels $\left(\mathrm{Ca}_{\mathrm{v}} 3.1-3\right)$ possess a lysine $(\mathrm{K})$.

known $(3,4)$. Findings of previous studies indicated that the $\mathrm{Ca}^{2+}$ channel pore contains only a single high-affinity binding site and that ions compete for binding moieties $(9,10)$. Dang and McCleskey (7) revealed the stepwise model, which has a single high-affinity $\mathrm{Ca}^{2+}$ binding site flanked by two lowaffinity divalent cation binding sites, each composed of two carboxyl groups from the EEEE locus. Newer structure-based models have aimed to define the volume of the $\mathrm{Ca}^{2+}$ channel pore using structure theory. The ionic diameter of $\mathrm{Ba}^{2+}$ is much larger than that of $\mathrm{Ca}^{2+}$ and the resulting $\mathrm{Ba}^{2+}$ ions show a higher degree of crowding in the pore, causing a faster exit rate and larger conductance (11-13).

Mutagenesis studies indicate that the glutamate residue in the pore of domain III is the important determinant for ion permeation $(9,10,14-16)$. The domain III pore segments of all 10 families of voltage-gated $\mathrm{Ca}^{2+}$ channels (Fig. 1B) are highly conserved. All L-type $\mathrm{Ca}^{2+}$ channels $\left(\mathrm{Ca}_{\mathrm{V}} 1.1-4\right)$ possess a phenylalanine $(\mathrm{F})$ at position 1144 , located next to Glu-1145. However, all non-L-type high-voltage-activated $\mathrm{Ca}^{2+}$ channels $\left(\mathrm{Ca}_{\mathrm{v}} 2.1-3\right)$ possess a glycine $(\mathrm{G})$ and all low-voltageactivated $\mathrm{Ca}^{2+}$ channels $\left(\mathrm{Ca}_{\mathrm{v}} 3.1-3\right)$ possess a lysine $(\mathrm{K})$. The physicochemical properties of the amino acid residue at position 1144 are important to the permeation of multiple $\mathrm{Ba}^{2+}$ and $\mathrm{Ca}^{2+}$ ions through the pore (17). Amino acid substitutions at position 1144 of the $\mathrm{Ca}_{\mathrm{v}} 1.2$ channel reduce barium currents without affecting calcium currents. Therefore, we substituted

Phe-1144 (F) with $\mathrm{G}(\mathrm{F} / \mathrm{G})$ and $\mathrm{K}(\mathrm{F} / \mathrm{K})$ and observed the effects of mutation on the voltage and concentration dependency of AMFE.

\section{Materials and methods}

Amino acid residue substitution. Site-directed mutagenesis was used to substitute amino acid residues. Mutant fragments of the channel were generated by polymerase chain reaction (PCR) using mutagenic primers. The mutant PCR products were gel-purified, digested using restriction endonucleases and subcloned into a digested $\mathrm{Ca}_{\mathrm{V}} 1.2$ vector. The presence of the mutation and the integrity of each mutant were confirmed by qualitative restriction map analysis and directional DNA sequence analysis of the entire subcloned region. Functional expression of the mutant cDNAs was confirmed by western blot analysis and whole-cell patch-clamp electrophysiology.

Cell culture and transfections. HEK 293 cells were grown at $37^{\circ} \mathrm{C}$ in $6 \% \mathrm{CO}_{2}$ and DMEM-F12 medium supplemented with $10 \%$ fetal bovine serum and $1 \%$ penn-strep antibiotics. cDNAs encoding wild-type and mutant $\mathrm{Ca}_{\mathrm{v}} 1.2$ channels were co-transfected with $\alpha_{2} \delta$ (18), $\beta_{2}$ a (19) and $\mathrm{CaM}_{1234}$ (20) into HEK293 cells by calcium phosphate precipitation, as previously described $(17,20,21)$. $\mathrm{CaM}_{1234}$ was used to eliminate complications that could arise from $\mathrm{Ca}^{2+} / \mathrm{CaM}$-dependent changes in channel gating, as it encodes an inactive form of calmodulin that has been shown to eliminate $\mathrm{Ca}^{2+}$-dependent inactivation and facilitation (17,20-24). All cDNAs were expressed using pcDNA3 mammalian expression plasmids (Invitrogen, Carlsbad, CA, USA).

Patch-clamp electrophysiology. Whole-cell patch-clamp recordings were obtained as previously described $(17,21)$. Briefly, whole-cell currents were recorded at room temperature 2-3 days following transfection. Pipettes were pulled from borosilicate glass using a P-97 Flaming/Brown micropipette puller (Sutter Instruments, Novato, CA, USA) and fire-polished on an MF200 microforge (World Precision Instruments, Sarasota, FL, USA). External solutions contained: N-methylD-glutamine (NMG)-aspartate, $130 \mathrm{mM}$; HEPES, $10 \mathrm{mM}$; 4-aminopyridine, $10 \mathrm{mM}$. $\mathrm{BaCl}_{2}$ and $\mathrm{CaCl}_{2}$ were used to give the desired molar ratio of the two ions and the total divalent cation concentration was maintained at 2,10 or $20 \mathrm{mM}$. The osmolarity was adjusted to $300 \mathrm{mmol} / \mathrm{kg}$ with glucose and the $\mathrm{pH}$ was adjusted to 7.4 using $1 \mathrm{mM}$ NMG base solution. Pipettes had resistances of 2.5-3.0 M $\Omega$ when filled with internal solution. The peak tail currents were evoked at potentials from -90 to $+50 \mathrm{mV}$ of all channels at each ion concentration.

Data acquisition and analysis. Data were acquired using a HEKA EPC-9/2 amplifier and PULSE/PULSEFIT software (HEKA Electronik, Lambrecht, Germany). Leak and capacitive transients were corrected by $-\mathrm{P} / 4$ compensation. Series resistance was $<6 \mathrm{M} \Omega$ and compensated to $70 \%$. Tail currents were sampled at $50 \mathrm{kHz}$ and filtered at $5.0 \mathrm{kHz}$. Pulse protocols are described in each figure legend. Data analysis was performed using FitMaster (HEKA Electronik) and Origin 7 (OriginLab, Northampton, MA, USA). The significance of differences for the smallest normalized current and 

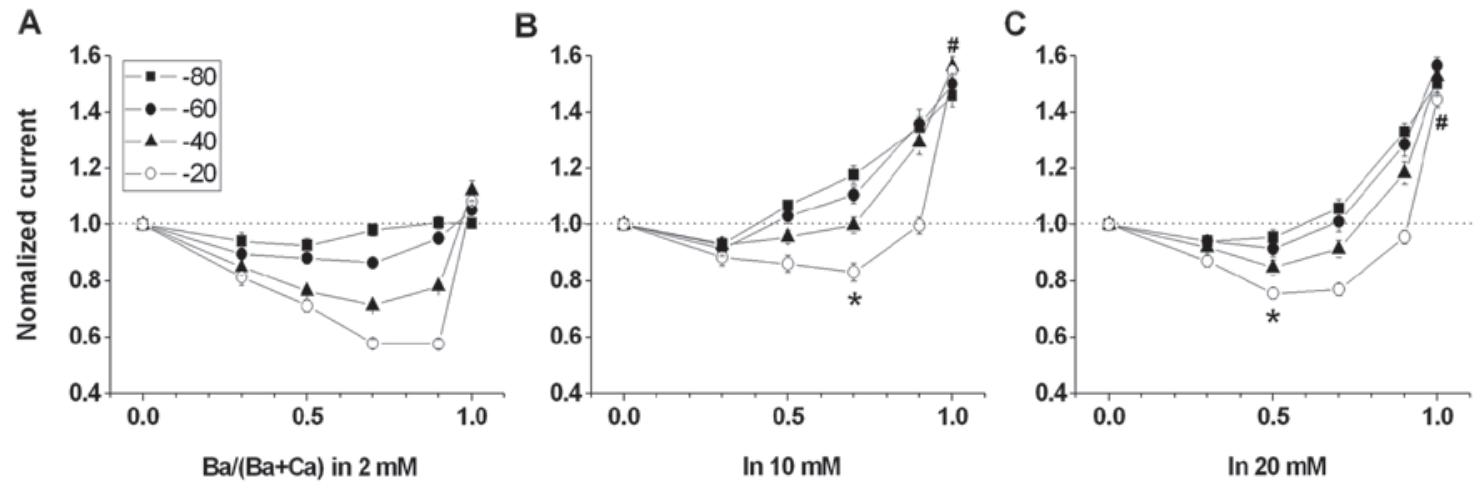

Wild-type

Figure 2. Voltage and concentration dependency of $\mathrm{I}_{\mathrm{Ba}} / \mathrm{I}_{\mathrm{Ca}}$ and the anomalous mole fraction effect (AMFE) for wild-type channels. Cells were stepped from a holding potential of -90 to $+50 \mathrm{mV}$ for $100 \mathrm{msec}$, and peak tail currents were measured at molar ratios of external $\mathrm{Ba}^{2+}$ to total divalent cation concentrations $\left[\mathrm{Ba}^{2+} /\left(\mathrm{Ba}^{2+}+\mathrm{Ca}^{2+}\right)\right]$ of $0.0,0.3,0.5,0.7,0.9$ and 1.0. The combined divalent concentration $\left(\mathrm{Ba}^{2+}+\mathrm{Ca}^{2+}\right)$ at each data point was kept at $(\mathrm{A}) 2$, (B) 10 and (C) $20 \mathrm{mM}$, respectively. AMFE is observed when peak tail currents, normalized to 1.0 when $\mathrm{Ba}^{2+} /\left(\mathrm{Ba}^{2+}+\mathrm{Ca}^{2+}\right)=0$, are plotted against $\mathrm{Ba}^{2+} /\left(\mathrm{Ba}^{2+}+\mathrm{Ca}^{2+}\right)$ at holding potentials of $-80,-60,-40$ and $-20 \mathrm{mV}$. The dashed line corresponds to peak tail currents measured in an external solution containing $0.0 \mathrm{mM} \mathrm{Ba}^{2+}$. (A) AMFE is evident at $2 \mathrm{mM}$ combined divalent concentration. The most pronounced AMFE is at a holding potential of $-20 \mathrm{mV}$. The smallest normalized current is $0.576 \pm 0.018\left[\mathrm{Ba}^{2+} /\left(\mathrm{Ba}^{2+}+\mathrm{Ca}^{2+}\right)=0.9\right]$ and $\mathrm{I}_{\mathrm{Ba}} / \mathrm{I}_{\mathrm{Ca}}$ is $1.082 \pm 0.035, \mathrm{n}=6$. (B) AMFE is evident at $10 \mathrm{mM}$ combined divalent concentration. The most pronounced AMFE is at a holding potential of $-20 \mathrm{mV}$. The smallest normalized current is $0.831 \pm 0.033\left[\mathrm{Ba}^{2+} /\left(\mathrm{Ba}^{2+}+\mathrm{Ca}^{2+}\right)=0.7\right]$ and $\mathrm{I}_{\mathrm{Ba}} / \mathrm{I}_{\mathrm{Ca}}$ is $1.547 \pm 0.052$, $\mathrm{n}=9$. Each is different from that at $2 \mathrm{mM}$ combined divalent concentration and shown as "*, and "\#, respectively. (C) AMFE is evident at $20 \mathrm{mM}$ combined divalent concentration. The most pronounced AMFE is at a holding potential of $-20 \mathrm{mV}$. The smallest normalized current is $0.769 \pm 0.022\left[\mathrm{Ba}^{2+} /\left(\mathrm{Ba}^{2+}+\mathrm{Ca}^{2+}\right)=\right.$ $0.5]$ and $\mathrm{I}_{\mathrm{Ba}} / \mathrm{I}_{\mathrm{Ca}}$ is $1.445 \pm 0.027, \mathrm{n}=9$. Each is different from that at $2 \mathrm{mM}$ combined divalent concentration and shown as "*' and '\#', respectively.

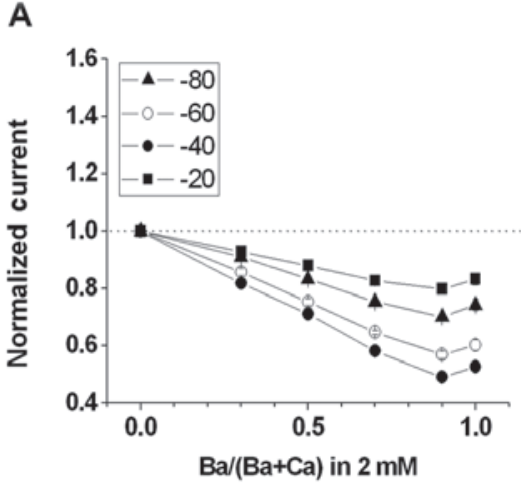

B

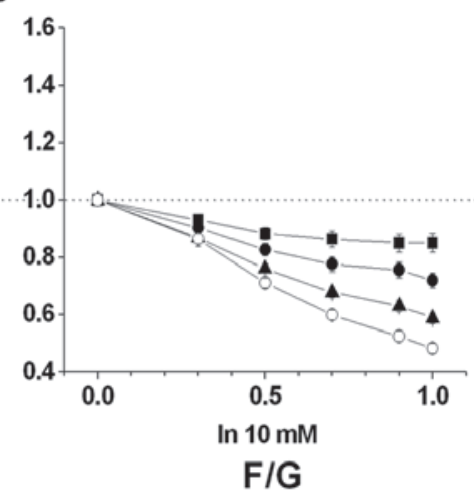

C

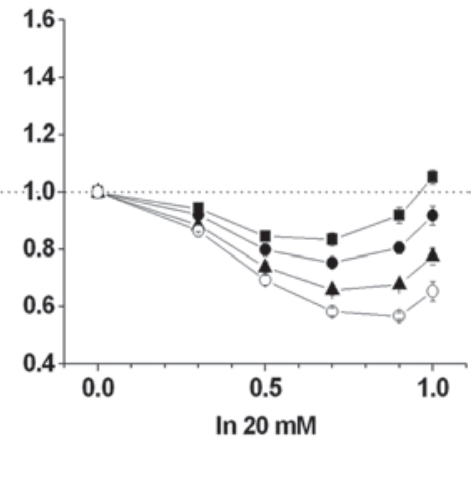

Figure 3. Voltage and concentration dependency of $\mathrm{I}_{\mathrm{Ba}} / \mathrm{I}_{\mathrm{Ca}}$ and the anomalous mole fraction effect (AMFE) for F/G mutant channels. Cells were stepped from a holding potential of -90 to $+50 \mathrm{mV}$ for $100 \mathrm{msec}$, and peak tail currents were measured at molar ratios of external $\mathrm{Ba}^{2+}$ to total divalent cation concentrations $\left[\mathrm{Ba}^{2+} /\left(\mathrm{Ba}^{2+}+\mathrm{Ca}^{2+}\right)\right]$ of 0.0, 0.3, 0.5, 0.7, 0.9 and 1.0. The combined divalent concentration $\left(\mathrm{Ba}^{2+}+\mathrm{Ca}^{2+}\right)$ at each data point was kept at $2(\mathrm{~A} ; \mathrm{n}=8), 10(\mathrm{~B} ; \mathrm{n}=9)$ and $20 \mathrm{mM}(\mathrm{C} ; \mathrm{n}=6)$, respectively. The dashed line corresponds to peak tail currents measured in an external solution containing $0.0 \mathrm{mM} \mathrm{Ba}^{2+}$.

$\mathrm{I}_{\mathrm{Ba}} / \mathrm{I}_{\mathrm{Ca}}$ among wild-type, $\mathrm{F} / \mathrm{G}$ and $\mathrm{F} / \mathrm{K}$ channels were analyzed using one-way ANOVA with Tukey's test. The significance of differences between wild-type and $\mathrm{F} / \mathrm{K}$ was analyzed using two-sample independent t-tests. Data were reported as the means \pm SE. Statistically significant results $(P<0.05)$ are indicated in the figures by an asterisk or a pound sign.

\section{Results}

$F / G$ does not promote AMFE. Unlike wild-type channels (Fig. 2), the tail current amplitudes for $\mathrm{F} / \mathrm{G}$ were reduced almost monotonically as $\mathrm{Ba}^{2+} /\left(\mathrm{Ba}^{2+}+\mathrm{Ca}^{2+}\right)$ progressed to 0.7 , but failed to increase as $\mathrm{Ba}^{2+} /\left(\mathrm{Ba}^{2+}+\mathrm{Ca}^{2+}\right)$ approached 1.0 in 2 and $10 \mathrm{mM}$ external solutions (Fig. 3A and B). The relative current amplitudes for $\mathrm{F} / \mathrm{G}$ were indistinguishable when $\mathrm{Ba}^{2+} /$
$\left(\mathrm{Ba}^{2+}+\mathrm{Ca}^{2+}\right)=1.0$. However, as shown in Fig. 3C, the tail current amplitudes for $\mathrm{F} / \mathrm{G}$ increased as $\mathrm{Ba}^{2+} /\left(\mathrm{Ba}^{2+}+\mathrm{Ca}^{2+}\right)$ approached 1.0 in $20 \mathrm{mM}$ external solution. Compared with a previous report (25), we found that the conditions at $20 \mathrm{mM}$ for F/G did not detect AMFE, as the maximum AMFE appeared when the total divalent cation concentrations were kept low (i.e., $2 \mathrm{mM}$ ).

Voltage and concentration dependency of $I_{B a} / I_{C a}$. The experimental conditions were established to detect changes in AMFE at a varied series of recording holding voltages and combined divalent concentrations. The AMFE was determined by measuring peak tail currents in the presence of various molar ratios of $\mathrm{Ca}^{2+}$ and $\mathrm{Ba}^{2+}$. Under conditions that promote AMFE, a difference was detected for wild-type and F/K channels, 

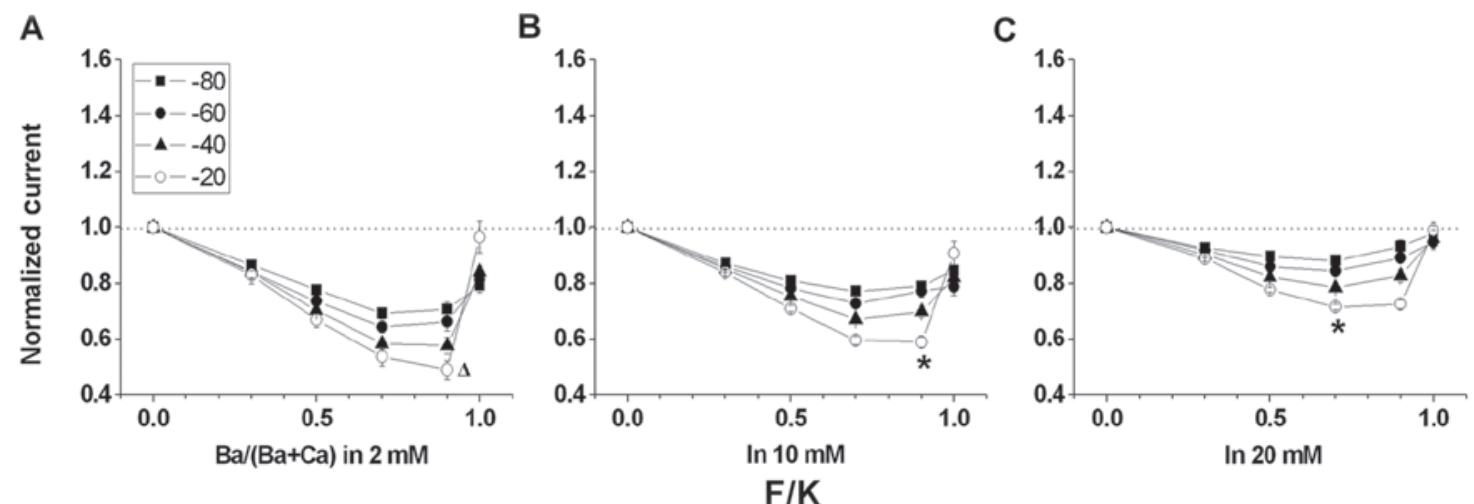

Figure 4. Voltage and concentration dependency of $\mathrm{I}_{\mathrm{Ba}} / \mathrm{I}_{\mathrm{Ca}}$ and the anomalous mole fraction effect (AMFE) for F/K mutant channels. Cells were stepped from a holding potential of -90 to $+50 \mathrm{mV}$ for $100 \mathrm{msec}$, and peak tail currents were measured at molar ratios of external Ba ${ }^{2+}$ to total divalent cation concentrations $\left[\mathrm{Ba}^{2+} /\left(\mathrm{Ba}^{2+}+\mathrm{Ca}^{2+}\right)\right]$ of 0.0, 0.3, 0.5, 0.7, 0.9 and 1.0. The combined divalent concentration $\left(\mathrm{Ba}^{2+}+\mathrm{Ca}^{2+}\right)$ at each data point was kept at (A) 2, (B) 10 and (C) $20 \mathrm{mM}$, respectively. AMFE is observed when peak tail currents, normalized to 1.0 when $\mathrm{Ba}^{2+} /\left(\mathrm{Ba}^{2+}+\mathrm{Ca}^{2+}\right)=0$, are plotted against $\mathrm{Ba}^{2+} /\left(\mathrm{Ba}^{2+}+\mathrm{Ca}^{2+}\right)$ at holding potentials of $-80,-60,-40$ and $-20 \mathrm{mV}$. The dashed line corresponds to peak tail currents measured in an external solution containing $0.0 \mathrm{mM} \mathrm{Ba}^{2+}$. (A) AMFE is evident at $2 \mathrm{mM}$ combined divalent concentration. The most pronounced AMFE is at a holding potential of $-20 \mathrm{mV}$. The smallest normalized current is $0.491 \pm 0.021\left[\mathrm{Ba}^{2+} /\left(\mathrm{Ba}^{2+}+\mathrm{Ca}^{2+}\right)=0.9\right]$ and $\mathrm{I}_{\mathrm{Ba}} / \mathrm{I}_{\mathrm{Ca}}$ is $0.966 \pm 0.440, \mathrm{n}=5$. The smallest normalized current of $\mathrm{F} / \mathrm{K}$ is distinguished from that of wild-type $(\Delta)$. (B) AMFE is evident at $10 \mathrm{mM}$ combined divalent concentration. The most pronounced AMFE is at a holding potential of $-20 \mathrm{mV}$. The smallest normalized current is $0.590 \pm 0.019\left[\mathrm{Ba}^{2+} /\left(\mathrm{Ba}^{2+}+\mathrm{Ca}^{2+}\right)=0.9\right]$, which is different from that at $2 \mathrm{mM}$ combined divalent concentration and shown as an asterisk and $\mathrm{I}_{\mathrm{Ba}} / \mathrm{I}_{\mathrm{Ca}}$ is $0.908 \pm 0.044, \mathrm{n}=8$. (C) AMFE is evident at $20 \mathrm{mM}$ of the combined divalent concentration. The most pronounced AMFE is at a holding potential of $-20 \mathrm{mV}$. The smallest normalized current is $0.716 \pm 0.010\left[\mathrm{Ba}^{2+} /\left(\mathrm{Ba}^{2+}+\mathrm{Ca}^{2+}\right)=0.7\right]$, which is different from that at $2 \mathrm{mM}$ combined divalent concentration and shown as ‘*, and $\mathrm{I}_{\mathrm{Ba}} / \mathrm{I}_{\mathrm{Ca}}$ is $0.990 \pm 0.027, \mathrm{n}=9$.

$\mathrm{I}_{\mathrm{Ba}} / \mathrm{I}_{\mathrm{Ca}}$ determined at the concentration of $2 \mathrm{mM}$ compared with $\mathrm{I}_{\mathrm{Ba}} / \mathrm{I}_{\mathrm{Ca}}$ determined at higher concentrations (i.e., 10 and $20 \mathrm{mM}$ ) (Figs. 2 and 4). Furthermore, we plotted the voltage range of -80 to $-20 \mathrm{mV}$ at which we could record the clear peak tail current of all three types of channels at each ion concentration. For each category of wild-type and $\mathrm{F} / \mathrm{K}$ channels, $\mathrm{I}_{\mathrm{Ba}} /$ $\mathrm{I}_{\mathrm{Ca}}$ values were similar at each ion concentration, while tail currents were evoked at potentials from -80 to $-20 \mathrm{mV}$. These observations suggest that the extracellular divalent ion concentration is a critical parameter in determining the selectivity properties of the pore.

Voltage and concentration dependence of AMFE. The AMFE of the indicated holding voltages and external solution concentrations for wild-type and mutant channels were recorded, respectively. While the holding potential declined from -80 to $-20 \mathrm{mV}$, AMFEs for wild-type and $\mathrm{F} / \mathrm{K}$ channels became more pronounced (Figs. 2 and 4). The smallest normalized currents exhibited differently when the total divalent cation concentrations remained at $2 \mathrm{mM}$ compared to 10 or $20 \mathrm{mM}$ (Fig. 2). Consistent with a previous report (25), AMFE was greatest when tail currents were evoked at relatively positive potentials $(-20 \mathrm{mV})$ and when the total divalent cation concentrations were kept low (i.e., $2 \mathrm{mM}$ ).

The AMFE can be attenuated or accentuated by pore substitution. The normalized current for wild-type in $2 \mathrm{mM}$ external solution decreased to $\sim 0.58$ when $\mathrm{Ba}^{2+} /\left(\mathrm{Ba}^{2+}+\mathrm{Ca}^{2+}\right)$ $=0.9$ before rapidly climbing to $\sim 1.08$ as $\mathrm{Ba}^{2+} /\left(\mathrm{Ba}^{2+}+\mathrm{Ca}^{2+}\right)$, approaching 1.0 (Fig. 2A). In contrast to F/G (Fig. 3), F/K (Fig. 4) exhibited robust AMFE, similar to wild-type. The relative current amplitudes for $\mathrm{F} / \mathrm{K}$ are indistinguishable when $\mathrm{Ba}^{2+} /\left(\mathrm{Ba}^{2+}+\mathrm{Ca}^{2+}\right)=1$, yet $\mathrm{F} / \mathrm{K}$ presents an AMFE, indicating that the $\mathrm{I}_{\mathrm{Ba}} / \mathrm{I}_{\mathrm{Ca}}$ and AMFE may be altered independently. In $2 \mathrm{mM}$ external solution the AMFE for F/K (Fig. 4A) was greater than that for wild-type (Fig. 2A) and the normalized current for $\mathrm{F} / \mathrm{K}$ reached a minimum value of 0.49 compared with 0.58 for wild-type.

\section{Discussion}

General. Mutagenesis was applied in the pore segment to assess the effects on the voltage and concentration dependency of $\mathrm{I}_{\mathrm{Ba}} / \mathrm{I}_{\mathrm{Ca}}$ and the AMFE of $\mathrm{Ca}_{\mathrm{v}} 1.2$ channels. Of the substitutions investigated in this study, $\mathrm{F} / \mathrm{G}$ does not promote AMFE. However, F/K exhibits the voltage and concentration dependence of AMFE, which is more pronounced than that of wild-type channels.

Glycine and lysine substitutions of Phe-1144 affect AMFE through different mechanisms. The multi-ion interaction within the pore of the $\mathrm{Ca}^{2+}$ channel has long been a topic of research. Traditional theories $(3,4)$ have indicated that an electrostatic interaction occurs between one ion bound to the pore and a second entering the pore. The electrostatic interaction causes an intricate adjustment of the conductance and activity relationship between the ions. The phenomenon of AMFE is an important demonstration of this interaction. AMFE appears when a mixture of two classes of permeant ions generates less current than either class of permeant ion alone. AMFE is an intricate phenomenon that is determined by the holding voltage and total ion concentration, as well as the inherent binding characteristics of the channel. Thus, AMFE is a significant biophysical probe of ion-ion interactions in the open pore of VGCCs.

Furthermore, Williamson and Sather (26) suggested that the unitary channel conductance is proportional to the volume of the side chain introduced by the amino acid residue at position 1144 adjacent to the residue of the selectivity filter. As the van der Waals volume of the positively charged lysine 
is similar to that of phenylalanine, $\mathrm{F} / \mathrm{K}$ would be expected to demonstrate conductance resembling that of wild-type. However, a previous finding (17) that revealed the $\mathrm{Ba}^{2+}$ conductance of $\mathrm{F} / \mathrm{K}$ is similar to that of $\mathrm{F} / \mathrm{G}$ but not wildtype, is not compatible with this hypothesis. We suggest that Glu-1145 may produce a more restricted interaction with its neighboring residue as a positively charged lysine but a less restricted interaction with its neighboring residue as a neutral glycine. Moreover, one would predict that there are extra subtle differences between the conductance properties of the two mutants as both $\mathrm{F} / \mathrm{G}$ and $\mathrm{F} / \mathrm{K}$ reduce $\mathrm{Ba}^{2+}$ currents (17). Such differences may be further revealed by observing their respective AMFEs.

We studied AMFE at a variety of voltages and concentrations to examine how the mutations would affect ion-ion interactions in the open pore of $\mathrm{Ca}^{2+}$ channels. The results indicate that AMFE for $\mathrm{F} / \mathrm{G}$ is lower than that for wild-type, while for $\mathrm{F} / \mathrm{K}$ it is more pronounced than that for wild-type, although the voltage and concentration dependency remain the same. These results suggest that the characteristics of the amino acid residue at position 1144 are capable of accentuating or attenuating the AMFE. Thus, the finding that glycine and lysine substitutions at position 1144 are important determinants in modifying the AMFE suggests that $\mathrm{F} / \mathrm{G}$ and $\mathrm{F} / \mathrm{K}$ reduce $\mathrm{Ba}^{2+}$ conductance through different mechanisms.

Phe-1144 substitutions confer to structure-based models for $\mathrm{Ca}^{2+}$ channel permeation. The pore selectivity filter, the EEEE locus, is the critical structure for high $\mathrm{Ca}^{2+}$ selectivity while simultaneously promoting the high rates of $\mathrm{Ca}^{2+}$ flux of the voltage-gated calcium channel, as it forms the $\mathrm{Ca}^{2+}$ binding site (27). However, our findings are consistent with an increasing number of studies indicating that residues near or even far from the EEEE locus also participate in channel permeation $(21,26,28,29)$. The traditional two-site, three-barrier models for the fundamental properties of ion selectivity and permeation through $\mathrm{Ca}^{2+}$ channels are based on measurable forces and binding energies. Therefore, these models cannot be used for channel structural studies, as the forces and binding energies cannot be measured for realistic channel structures. There are several later models based on structures to simulate many of the biophysical characteristics of ion permeation for the $\mathrm{Ca}^{2+}$ channel pore (11-13,30-32).

Lipkind and Fozzard (12) suggested a structural model that may be considered as a structural correlate to the stepwise model of Dang and McCleskey (7). The former model concludes that there are three binding sites formed by the eight carboxyl groups from the EEEE locus: a central, single high-affinity divalent cation binding site composed of four of the carboxyl groups flanked by two low-affinity divalent cation binding sites on either side, each composed of two carboxyl groups. On the basis of this model, we conclude that substitutions at position 1144 change the interactions between one of the two low-affinity binding sites and $\mathrm{Ba}^{2+}$.

The early barrier models $(3,4)$ proposed that the selectivity filter has a defined volume. Furthermore, newer models $(10,11,13,31)$ proposed that the volume is formed by the eight carbonyl oxygen atoms from the EEEE locus. Wang et al (17) used the 'volume exclusion/charge neutralization' model to explain the reduced conductance of $\mathrm{Ba}^{2+}$ but not $\mathrm{Ca}^{2+}$ in the pores of the $\mathrm{F} / \mathrm{G}$ mutant channels. The crystal diameters of $\mathrm{Ca}^{2+}$ and $\mathrm{Na}^{+}$ions are almost equal (2.00 vs. $2.04 \AA$, respectively), but each $\mathrm{Ca}^{2+}$ ion carries twice as much charge as an $\mathrm{Na}^{+}$ion. Thus, $\mathrm{Ca}^{2+}$ is capable of neutralizing the highly negatively charged EEEE to bind tightly to the selectivity filter without the overcrowding suspected for monovalent cations such as $\mathrm{Na}^{+} . \mathrm{Ba}^{2+}$ and $\mathrm{Ca}^{2+}$ ions carry the same charge, but the ionic diameter of $\mathrm{Ba}^{2+}$ is $\sim 36 \%$ larger than that of $\mathrm{Ca}^{2+}$ (2.72 vs. $2.00 \AA$, respectively). Thus, for wild-type channels, $\mathrm{Ba}^{2+}$ ions are expected to exhibit a higher degree of crowding than $\mathrm{Ca}^{2+}$ ions, as multiple ions attempt to bind and neutralize the negatively charged EEEE, resulting in an increasing exit rate, lower binding affinity and higher conductance relative to $\mathrm{Ca}^{2+}$. Our results resemble this 'volume exclusion/charge neutralization' model. The substitutions at position 1144 are assumed to alter the geometry and/or electrostatic context of the selectivity filter, in order to lessen the capability of overcrowding by $\mathrm{Ba}^{2+}$ ions, allowing it to contain multiple larger $\mathrm{Ba}^{2+}$ ions; however, its ability to contain multiple $\mathrm{Ca}^{2+}$ ions changes little.

Residues at position 1144 participate in the permeation of several classes of voltage-gated $\mathrm{Ca}^{2+}$ channels. Results of the present study have shown that non-glutamate residues in the pore of L-type $\mathrm{Ca}^{2+}$ channels change the characteristics of ion permeation. The $\mathrm{Ca}_{\mathrm{v}} 3$-like mutant channel tested, $\mathrm{F} / \mathrm{K}$, promoted the AMFE phenomenon that was more comparable with $\mathrm{Ca}_{\mathrm{v}} 1.2$ channels than $\mathrm{Ca}_{\mathrm{v}} 2$ channels. Thus, the non-glutamate residues are critical for determining the permeability characteristics of voltage-gated $\mathrm{Ca}^{2+}$ channels. There are an increasing number of other studies also supporting this conclusion $(17,21,26,28,29,33)$. Our previous study substituted an outer vestibule amino acid, Glu-1126, of $\mathrm{Ca}_{\mathrm{V}} 1.2$ channels and revealed that the preference of the channel is approximately halved for passing $\mathrm{Ba}^{2+}$, but remains the same for passing $\mathrm{Ca}^{2+}(21)$. Even substitutions as far as 100 residues upstream of EEEE in $\mathrm{Ca}_{\mathrm{v}} 2.2$ channels reduce the preference of the channel for passing $\mathrm{Ba}^{2+}$ over $\mathrm{Ca}^{2+}$ currents (33). Regardless of the precise mechanism and simulation, our results provide further support for how the nonglutamate residues participate in an electrostatic and chemical environment contributing to ion permeation. More specifically, we have investigated the voltage and concentration dependence of the AMFE phenomenon of substituting mutant channels. The consequences of this study are likely to expand the understanding of the molecular mechanisms contributing to ion permeation of VGCCs.

Clinical implications. VGCCs are important in physiological functions of the cardiovascular system. They are critical factors of pathological changes in common or frequently encountered diseases of the cardiovascular system, such as arrhythmia, hypertension and coronary heart disease. Furthermore, they are functional targets of multiple commonly used drugs, such as calcium channel blockers. Ion permeation, as an essential biophysical property of VGCCs, is under close attention from investigators worldwide; however, its functional mechanisms have not been clearly elucidated. Explorations of the functional mechanisms of calcium channels to determine the essential qualities at the ion channel level of physiological and pathological phenomenon as well as investigating the theoretical 
basis at a molecular level of the pathogenesis and therapeutics of diseases are underway.

\section{Acknowledgements}

We are grateful for the financial support from the Superior Group Grant of Hubei Province Funding no. 2007ABC011 to C.-X.H. and the Special Grant for Basic Scientific Research Expenses of the Central Universities no. 302274994 to Z.L.

\section{References}

1. Catterall WA, Perez-Reyes E, Snutch TP and Striessnig J: International Union of Pharmacology. XLVIII. Nomenclature and structure-function relationships of voltage-gated calcium channels. Pharmacol Rev 57: 411-425, 2005.

2. Hille B: Ion Channels of Excitable Membranes. 3rd edition. Sinaur Associates, Sunderland, MA, pp649-662, 2001.

3. Hess P and Tsien RW: Mechanism of ion permeation through calcium channels. Nature 309: 453-456, 1984.

4. Almers W and McCleskey EW: Non-selective conductance in calcium channels of frog muscle: calcium selectivity in singlefile pore. J Physiol 353: 585-608, 1984.

5. Bourinet E, Zamponi GW, Stea A, et al: The alpha 1E calcium channel exhibits permeation properties similar to low-voltageactivated calcium channels. J Neurosci 16: 4983-4993, 1996.

6. Yue DT and Marban E: Permeation in the dihydropyridine-sensitive calcium channel. Multi-ion occupancy but no anomalous mole-fraction effect between $\mathrm{Ba}^{2+}$ and $\mathrm{Ca}^{2+}$. J Gen Physiol 95: 911-939, 1990.

7. Dang TX and McCleskey EW: Ion channel selectivity through stepwise changes in binding affinity. J Gen Physiol 111: 185-193, 1998.

8. Kostyuk PG, Mironov SL and Shuba YM: Two ion-selecting filters in the calcium channel of the somatic membrane of mollusc neurons. J Membr Biol 76: 83-93, 1983.

9. Yang J, Ellinor PT, Sather WA, Zhang JF and Tsien RW: Molecular determinants of $\mathrm{Ca}^{2+}$ selectivity and ion permeation in L-type $\mathrm{Ca}^{2+}$ channels. Nature 366: 158-161, 1993.

10. Ellinor PT, Yang J, Sather WA, Zhang JF and Tsien RW: $\mathrm{Ca}^{2+}$ channel selectivity at a single-locus for high-affinity $\mathrm{Ca}^{2+}$ interactions. Neuron 15: 1121-1132, 1995.

11. Corry B, Allen TW, Kuyucak S and Chung SH: Mechanisms of permeation and selectivity in calcium channels. Biophys J 80 : 195-214, 2001.

12. Lipkind GM and Fozzard HA: Modeling of the outer vestibule and selectivity filter of the L-type $\mathrm{Ca}^{2+}$ channel. Biochemistry 40: 6786-6794, 2001.

13. Nonner W, Catacuzzeno L and Eisenberg B: Binding and selectivity in L-type calcium channels: a mean spherical approximation. Biophys J 79: 1976-1992, 2000.

14. Kim MS, Morii T, Sun LX, Imoto K and Mori Y: Structural determinants of ion selectivity in brain calcium channel. FEBS Lett 318: 145-148, 1993 .

15. Mikala G, Bahinski A, Yatani A, Tang SQ and Schwartz A Differential contribution by conserved glutamate residues to an ion-selectivity site in the L-type $\mathrm{Ca}^{2+}$ channel pore. FEBS Lett 335: 265-269, 1993.
16. Tang SQ, Mikala G, Bahinski A, Yatani A, Varadi G and Schwartz A: Molecular localization of ion selectivity sites within the pore of a human L-type cardiac calcium-channel. J Biol Chem 268: 13026-13029, 1993

17. Wang X, Ponoran TA, Rasmusson RL, Ragsdale DS and Peterson BZ: Amino acid substitutions in the pore of the $\mathrm{Ca}(\mathrm{V}) 1.2$ calcium channel reduce barium currents without affecting calcium currents. Biophys J 89: 1731-1743, 2005.

18. Tomlinson WJ, Stea A, Bourinet E, Charnet P, Nargeot J and Snutch TP: Functional properties of a neuronal class C L-type calcium channel. Neuropharmacology 32: 1117-1126, 1993.

19. Perez-Reyes E, Castellano A, Kim HS, et al: Cloning and expression of a cardiac/brain beta subunit of the L-type calcium channel. J Biol Chem 267: 1792-1797, 1992.

20. Peterson BZ, DeMaria CD, Adelman JP and Yue DT: Calmodulin is the $\mathrm{Ca}^{2+}$ sensor for $\mathrm{Ca}^{2+}$-dependent inactivation of L-type calcium channels. Neuron 22: 549-558, 1999.

21. Li Z, Wang XM, Gao GF, et al: A single amino acid change in $\mathrm{Ca}(\mathrm{V}) 1.2$ channels eliminates the permeation and gating differences between $\mathrm{Ca}(2+)$ and $\mathrm{Ba}(2+)$. J Membr Biol 233: 23-33, 2010.

22. Peterson BZ, Lee JS, Mulle JG, Wang Y, de Leon M and Yue DT: Critical determinants of $\mathrm{Ca}^{2+}$-dependent inactivation within an EF-hand motif of L-type $\mathrm{Ca}^{2+}$ channels. Biophys J 78: 1906-1920, 2000.

23. Qin N, Olcese R, Bransby M, Lin T and Birnbaumer L: $\mathrm{Ca}^{2+}$ induced inhibition of the cardiac $\mathrm{Ca}^{2+}$ channel depends on calmodulin. Proc Natl Acad Sci USA 96: 2435-2438, 1999.

24. Zuhlke RD, Pitt GS, Deisseroth K, Tsien RW and Reuter H: Calmodulin supports both inactivation and facilitation of L-type calcium channels. Nature 399: 159-162, 1999.

25. Wakamori M, Strobeck M, Niidome T, Teramoto T, Imoto K and Mori Y: Functional characterization of ion permeation pathway in the N-type $\mathrm{Ca}^{2+}$ channel. J Neurophysiol 79: 622-634, 1998.

26. Williamson AV and Sather WA: Nonglutamate pore residues in ion selection and conduction in voltage-gated $\mathrm{Ca}^{2+}$ channels. Biophys J 77: 2575-2589, 1999.

27. Sather WA and McCleskey EW: Permeation and selectivity in calcium channels. Annu Rev Physiol 65: 133-159, 2003.

28. Dilmac N, Hilliard N and Hockerman GH: Molecular determinants of $\mathrm{Ca}^{2+}$ potentiation of diltiazem block and $\mathrm{Ca}^{2+}$-dependent inactivation in the pore region of $\mathrm{Ca}(\mathrm{v}) 1.2$. Mol Pharmacol 64: 491-501, 2003.

29. Dilmac N, Hilliard N and Hockerman GH: Molecular determinants of frequency dependence and $\mathrm{Ca}^{2+}$ potentiation of verapamil block in the pore region of $\mathrm{Ca}(\mathrm{v}) 1.2$. Mol Pharmacol 66: 1236-1247, 2004.

30. Nonner W and Eisenberg B: Ion permeation and glutamate residues linked by Poisson-Nernst-Planck theory in L-type calcium channels. Biophys J 75: 1287-1305, 1998.

31. Boda D, Henderson D and Busath DD: Monte Carlo simulations of the mechanism for channel selectivity: the competition between volume exclusion and charge neutrality. J Phys Chem 104: 11574-11577, 2001.

32. Gillespie D and Boda D: The anomalous mole fraction effect in calcium channels: a measure of preferential selectivity. Biophysi J 95: 2658-2672, 2008.

33. Feng ZP, Hamid J, Doering C, et al: Amino acid residues outside of the pore region contribute to N-type calcium channel permeation. J Biol Chem 276: 5726-5730, 2001. 